\title{
Does the COPD assessment test associate to skeletal muscle dysfunction in individuals with chronic obstructive pulmonary disease?
}

Tamires Daros dos Santos ${ }^{1}$ (1); Adriane Schmidt Pasqualoto ${ }^{2}$ (1); Felipe Fagundes Pereira ${ }^{3}$; Everton Ludke ${ }^{4}$ (1); Aron Ferreira da Silveira ${ }^{5}$ (1); Isabella Martins de Albuquerque ${ }^{6 *}$ (1)

\begin{abstract}
Background: Skeletal muscles provide the mechanical basis for breathing and movement, and skeletal muscle dysfunction which is frequently observed in individuals with chronic obstructive pulmonary disease (COPD) has important clinical implications. Aims: The objective of the present study was to investigate whether the COPD assessment test (CAT) score may be associated with quadriceps muscle thickness, handgrip strength, peripheral muscle endurance and respiratory muscle strength in individuals with COPD enrolled in a pulmonary rehabilitation program. Methods: This is a cross-sectional study with evaluation of the following outcomes: quadriceps muscle thickness (ultrasonography), handgrip strength (muscle strength dynamometer), peripheral muscle endurance (30-second sit-to-stand test) and respiratory muscle strength (manovacuometry). Results: Twenty-three individuals $(65 \pm 10.1$ years; GOLD I $(n=2)$, II $(n=8)$, III $(n=7)$ and IV $(n=6))$ participated in the study. The CAT score correlated negatively and moderately with handgrip strength $(r=-0.655 ; p<0.001)$, negatively and moderately with quadriceps muscle thickness $(r=-0.562 ; p=0.005)$ and peripheral muscle endurance $(r=-0.573 ; p=0.004)$. There was no correlation between CAT score and respiratory muscle strength. The multiple linear regression model including the variables quadriceps muscle thickness, handgrip strength and peripheral muscle endurance was the best to predict the CAT score, explaining $65 \%$ of the variance. Conclusions: Our results suggest that the CAT score was associated with skeletal muscle dysfunction through quadriceps muscle thickness, handgrip strength and peripheral muscle endurance in a sample composed predominantly of women with COPD, ex-smokers or without previous smoking history enrolled in a pulmonary rehabilitation program.
\end{abstract}

Keywords: Chronic Obstructive Pulmonary Disease; Ultrasonography; Muscle Strength; Dynamometer.

\section{How to cite}

Santos TD, Pasqualoto AS, Pereira FF, Ludke E, Silveira AF, Albuquerque IM. Does the COPD assessment test associate to skeletal muscle dysfunction in individuals with chronic obstructive pulmonary disease? Cardiorespir Physiother Crit Care Rehabil. 2021;1:e42146. https://doi.org/10.4322/2675-9977.cpcr.42146

\section{How can the results of this study be used in clinical practice?}

- The score obtained in the CAT was associated with skeletal muscle dysfunction through QMT, HGS and peripheral muscle endurance in individuals with COPD enrolled in a PR program demonstrating the importance of its applicability in the clinical practice of physiotherapists.

\author{
Submitted: November 19, 2020 \\ Study conducted at: Rehabilitation Unit of the \\ Hospital Universitário de Santa Maria (HUSM), \\ Universidade Federal de Santa Maria - UFSM, \\ Santa Maria, RS, Brasil. \\ Ethical approval: The study was approved by \\ the ethics committee (process no. 3,208,982) \\ of the Federal University of Santa Maria \\ (UFSM) in accordance with the guidelines of \\ the National Health Council in Resolution \\ 466/2012. \\ *Corresponding author: \\ Cidade Universitária, Bairro Camobi \\ . +55 (55) 3220-8234 \\ Programa de Pós-graduação em Distúrbios \\ Departamento de Fisioterapia e Reabilitação \\ graduação em Distúrbios \\ Brasil \\ Programa de Pós-graduação em Educação \\ Física, Santa Maria, RS, Brasil \\ Programa de Pós-graduação em Educação \\ Universias, Saria, RS, Brasil \\ - UFSM, Departamento de Morfologia, \\ da Comunicação Humana, Santa Maria, RS, \\ Departamento de Fisioterapia e Reabilitação, \\ Programa de Pós-graduação em Reabilitação \\ Funcional, Santa Maria, RS, Brasil
} unrestricted non-commercial use, distribution, and reproduction in any medium provided the original work is properly cited and is not represented as endorsing the use made of the work. Further, any new works must be made available under the same license. 


\section{INTRODUCTION}

Chronic obstructive pulmonary disease (COPD) is one of the main causes of morbidity and mortality, representing an important public health problem ${ }^{1}$. Currently, it has become the third most frequent cause of death and one of the main reasons for chronic hospitalization, resulting in a large expenditure of financial resources ${ }^{2}$.

Airflow limitation is one of the main clinical characteristics of individuals with COPD; this progressive and partially reversible ventilatory dysfunction occurs due to an abnormal pulmonary inflammatory process, which is triggered by exposure to particles and harmful gases ${ }^{1}$. Nevertheless, with the progression of the disease, a variety of systemic alterations occur, culminating in implications for the health-related quality of life (HRQoL) and patient's' prognosis ${ }^{3}$. Among the systemic consequences of COPD, there is the skeletal muscle dysfunction ${ }^{4}$.

Evidence has demonstrated that individuals with COPD present significant reduction in handgrip strength (HGS) when compared with controls ${ }^{5}$, quadriceps muscle weakness even in early stages of the disease and younger age groups ${ }^{6}$, reduction in both quadriceps muscle thickness $\left(\mathrm{QMT}^{7}\right.$ and quadriceps muscle resistance in comparison with healthy individuals ${ }^{8}$. Furthermore, changes in respiratory muscle strength (RMS) are frequent in these individuals ${ }^{9}$.

The skeletal muscles provide the mechanical basis for breathing and movement. Thus the skeletal muscle dysfunction observed in individuals with COPD has important clinical implications for the occurrence of symptoms, reduced functional capacity, increased frequency of health service use, impaired quality of life and reduced survival ${ }^{10-12}$. Therefore, a comprehensive evaluation of this outcome proves necessary.

In 2011 the Global Initiative for Chronic Obstructive Lung Disease (GOLD) guidelines introduced the COPD Assessment Test (CAT) to assess the clinical impact of COPD on health status. Since then, this instrument has been frequently used in both clinical practice and research, demonstrating reliability, validity and good responsiveness ${ }^{13}$. Recent meta-analysis demonstrated that the CAT score can be used as a complementary tool in clinical evaluation as a predictor of exacerbation, deterioration of health status, depression and even mortality in $\mathrm{COPD}^{14}$. Conversely, the possible relationship between variables reflecting skeletal muscle dysfunction and clinical impact on the health status of individuals with COPD has not been yet investigated.

Therefore, the aim of this study was to investigate whether the CAT score may be associated with QMT, HGS, peripheral muscle endurance and RMS in individuals with COPD entering a pulmonary rehabilitation (PR) program.

\section{METHODS}

\section{Study design}

Cross-sectional study conducted at the Rehabilitation Unit of the University Hospital of Santa Maria (HUSM),
Federal University of Santa Maria (UFSM), Santa Maria (RS), Brazil, from June to November 2019. The study was approved by the ethics committee (process no. 3.208.982) and in accordance with the guidelines of the National Health Council in Resolution 466/2012. All individuals provided written informed consent before participation.

The study sample consisted of patients recruited during the initial evaluation for admission to PR program referred by the local Pulmonology Department, with the clinical and spirometric diagnosis of COPD according to the criteria established by GOLD (forced expiratory volume in the first second/forced vital capacity - $\mathrm{FEV}_{1} / \mathrm{FVC}<70$ and $\mathrm{FEV}_{1}<80 \%$ of predicted $)^{1}$. Individuals who were active smokers, with coexistence of previously diagnosed neurological impairment, clinically unstable (acute exacerbation requiring hospitalization or use of systemic corticoids in the last 3 months), uncontrolled systemic arterial hypertension or in the presence of musculoskeletal disorders that would make it impossible to perform the evaluations proposed in this study ${ }^{1}$ were excluded from the study.

\section{Evaluations}

All individuals were submitted to two days of assessment, with a minimum 48-hour interval between them. On the first day, anamnesis, physical examination, application of the CAT questionnaire and assessment of RMS were performed. On the second day, QMT, HGS and peripheral muscle endurance evaluations were performed in this order. All assessments were performed by previously trained evaluators.

\section{COPD assessment test}

The Portuguese version of the CAT questionnaire, validated for the Brazilian population, was applied in an interview format to evaluate the health status ${ }^{15}$.

This instrument is composed of 8 items, each scoring from 0 to 5 , and the sum of these can be stratified into four categories that reflect the clinical impact of COPD symptoms on the life of individuals in: mild (CAT $=1-10)$, moderate $(\mathrm{CAT}=11-20)$, severe $(\mathrm{CAT}=21-30)$ and very severe $(\mathrm{CAT}=31-40)^{16}$.

\section{Respiratory muscle strength}

RMS was assessed by maximum inspiratory pressure (MIP) and maximum expiratory pressure (MEP) evaluated with an MVD 300 digital manometer (MDI $\left.{ }^{\circledR}, \mathrm{RS}, \mathrm{Brazil}\right)$. All measurements were done according to ATS/ERS recommendations (2002) ${ }^{17}$. The highest MIP and MEP values were used for analysis and compared to predicted values ${ }^{18}$.

\section{Quadriceps muscle thickness}

QMT was evaluated by high resolution ultrasound (US) (Mindray Ultrasound, DP-2200 portable, China), in B-mode, with echocardiological transducer (65C15EA 5.0-9.0 MHz, 
4W). Individuals were positioned in dorsal decubitus, with the transducer placed perpendicularly on their skin with minimal pressure at the midpoint of the quadriceps femoris, region located between the anterosuperior iliac spine and the upper patella pole ${ }^{19}$.

The measurement of the QMT was conducted using Image $\mathrm{J} \circledast$ software (NIH, Bethesda, MD) considering the average of three measurements with a maximum difference between them of $0.1 \mathrm{~cm}$ for each lower limb. The average of the QMT between the lower limbs was considered for analysis.

\section{Handgrip strength}

HGS was assessed by a previously calibrated mechanical dynamometer (Saehan corporation SH5001, Korea) ${ }^{20}$. In each evaluation, three maximum isometric effort attempts were recorded for 6 seconds, with a 1-minute interval between each one. For analysis, the mean of the three evaluations recorded in each upper limb, and after the mean between right and left upper limb were considered. The predicted values were calculated based on the equations of Novaes et al. ${ }^{21}$.

\section{Peripheral muscle endurance}

Peripheral muscle endurance was assessed by the 30 -second sit-to-stand (STS) test ${ }^{22}$. At the "go" signal, individuals were oriented to change their position to orthostatism, sequentially, returning to the chair in a sitting position and being encouraged to complete the largest number of repetitions for 30 seconds $^{22}$. The number of repetitions obtained in the aforementioned time interval was considered for analysis. The equations proposed by Tveter et al. ${ }^{23}$ were used in order to calculate the predicted values.

\section{Sample size calculation}

The sample size calculation was performed using BioEstat software (version 5.0), based on a pilot study in which the first 10 individuals were included. To detect a correlation of $\mathrm{r}=$ 0.60 between health status, evaluated by the total CAT score, and the HGS (mean between right and left upper limbs) with a significance level of $5 \%(\mathrm{p}<0.05)$ and statistical power of $80 \%$ a sample size of at least 20 individuals was calculated. The HGS variable was used as an indicator of overall strength ${ }^{24}$.

\section{Statistical analysis}

Data obtained were analyzed using GraphPad Prism 5 software (GraphPad Software Inc., San Diego, CA, USA). The normality of the variables was evaluated by the Shapiro-Wilk test. Continuous variables are presented in mean and standard deviation and categorical variables in absolute frequencies and percentages. The correlation between the total score obtained in the CAT with the other variables was assessed by Pearson's correlation coefficient, being considered weak $(\mathrm{r}=0.10-0.39)$, moderate $(\mathrm{r}=0.40-0.69)$ and strong $(\mathrm{r}=0.70$ 1.00) correlations ${ }^{25}$.
Simple linear regression and multiple linear regression analyses were performed using CAT as a dependent variable and QMT, HGS, peripheral muscle endurance and RMS as independent variables. Kruskal-Wallis test followed by Dunn's post-hoc was performed to compare values obtained for QMT, HGS, peripheral muscle endurance and RMS between CAT categories. The significance level adopted was $5 \%(\mathrm{p}<0.05)$.

\section{RESULTS}

Twenty-three individuals with COPD $(65 \pm 10.1$ years old, 14 female) enrolled in a PR program were included in this study (after the exclusion of three individuals because they were active smokers and two individuals by the use of systemic corticoids in the last 3 months). The anthropometric characteristics, lung function, disease impact and outcome variables are described on Table 1.

The total score obtained in the CAT correlated negatively and moderately with the mean of right and left QMT ( $\mathrm{r}=-$ $0.562 ; p=0.005$ ) (Figure 1A), negatively and moderately with the mean of right and left upper limb HGS $(r=-0.655 ; \mathrm{p}<0.001)$ (Figure 1B) and negatively and moderately with peripheral muscle endurance (Figure $1 \mathrm{C})(\mathrm{r}=-0.573 ; \mathrm{p}=0.004)$. However, there was no significant correlation between the total score obtained in the CAT with the MIP $(r=-0.372 ; \mathrm{p}=0.081)$ (Figure 1D) and the MEP ( $\mathrm{r}=-0.320 ; \mathrm{p}=0.137)$ (Figure 1E).

The multiple linear regression model including the variables QMT, HGS and peripheral muscle endurance was the best model to predict the CAT total score, explaining $65 \%$ of its variance (Table 2).

Taking into account the stratification into categories, which reflect the clinical impact of symptoms obtained through the CAT, there was a significant difference between mild and very severe scores for QMT mean; mild and severe, and mild and very severe for HGS mean; and mild and very severe for peripheral muscle endurance. However, there was no significant difference regarding the stratification into categories for RMS (MIP and MEP) (Figure 2).

\section{DISCUSSION}

To the best of our knowledge, this is the first study to investigate whether CAT score was associated with QMT, HGS, peripheral muscle endurance and RMS in individuals with COPD enrolled in a PR program. Our findings demonstrated that health status, as assessed by the CAT, correlated negatively and moderately with HGS, negatively and moderately with QMT and peripheral muscle endurance. Nevertheless, the CAT score did not show correlation with RMS. We also observed that the QMT, HGS and peripheral muscle endurance were predictors of the CAT score. Furthermore, our results suggest that individuals with low impact of COPD in health status had better QMT, HGS and peripheral muscle endurance values than those with a high impact. 
Table 1. Anthropometric characteristics, lung function, disease impact and outcome variables.

\begin{tabular}{|c|c|}
\hline Variables & Mean \pm SD $(n=23)$ \\
\hline \multicolumn{2}{|l|}{ Anthropometric } \\
\hline Age (years) & $64.6 \pm 10.1$ \\
\hline Female sex, n (\%) & $14(60.9)$ \\
\hline Body mass index $\left(\mathrm{kg} / \mathrm{m}^{2}\right)$ & $24.8 \pm 4.00$ \\
\hline \multicolumn{2}{|l|}{ Lung function } \\
\hline $\mathrm{FEV}_{1 /} \mathrm{FVC}$ (\%pred.) & $57.8 \pm 16.8$ \\
\hline $\mathrm{FEV}_{1}(\%$ pred.) & $50.1 \pm 17.1$ \\
\hline \multicolumn{2}{|l|}{ GOLD } \\
\hline I/II/III/IV, n (\%) & $2(8.7) / 8(34.8) / 7(30.4) / 6(26.1)$ \\
\hline CAT classification (score) & $19.4 \pm 8.9$ \\
\hline Mild, Mean \pm SD / n (\%) & $8.5 \pm 1.3 / 4(17.4)$ \\
\hline Moderate, Mean $\pm \mathrm{SD} / \mathrm{n}(\%)$ & $16.5 \pm 2.8 / 12(52.2)$ \\
\hline Severe, Mean \pm SD / n (\%) & $25.5 \pm 2.7 / 4(17.4)$ \\
\hline Very severe, Mean $\pm \mathrm{SD} / \mathrm{n}(\%)$ & $36.0 \pm 6.2 / 3(13.0)$ \\
\hline \multicolumn{2}{|l|}{ Outcome variables } \\
\hline $\mathrm{MIP}\left(\mathrm{cmH}_{2} \mathrm{O}\right)$ & $66.7 \pm 20.8$ \\
\hline MIP (\% pred.) & $97.2 \pm 30.9$ \\
\hline $\operatorname{MEP}\left(\mathrm{cmH}_{2} \mathrm{O}\right)$ & $82.4 \pm 19.7$ \\
\hline MEP (\% pred.) & $86.6 \pm 23.6$ \\
\hline QMT (mm) & $22.5 \pm 7.0$ \\
\hline $\begin{array}{l}\text { HGS right upper extremity } \\
(\mathrm{KgF})\end{array}$ & $25.9 \pm 7.5$ \\
\hline $\begin{array}{l}\text { HGS right upper extremity } \\
\text { (\%pred.) }\end{array}$ & $83.6 \pm 14.8$ \\
\hline $\begin{array}{l}\text { HGS left upper extremity } \\
(\mathrm{KgF})\end{array}$ & $24.8 \pm 8.0$ \\
\hline $\begin{array}{l}\text { HGS left upper extremity } \\
\text { (\%pred.) }\end{array}$ & $88.1 \pm 18.0$ \\
\hline $\begin{array}{l}\text { HGS mean right and left upper } \\
\text { extremities }\end{array}$ & $25.4 \pm 7.8$ \\
\hline $\begin{array}{l}30-\text { second sit-to-stand test } \\
\text { ( }{ }^{\circ} \text { of repetitions) }\end{array}$ & $8.2 \pm 1.9$ \\
\hline $\begin{array}{l}30 \text {-second sit-to-stand test } \\
\text { (\%pred.) }\end{array}$ & $38.3 \pm 14.8$ \\
\hline
\end{tabular}

Data are expressed as mean $\pm \mathrm{SD}$ or $\mathrm{n}(\%) . \mathrm{FEV}=$ forced expiratory volume in the first second; FVC = forced vital capacity; GOLD = Global Initiative for Chronic Obstructive Lung Disease; $\mathrm{CAT}=\mathrm{COPD}$ assessment test; $\mathrm{MIP}=$ maximum inspiratory pressure; $\mathrm{MEP}=$ maximum expiratory pressure $; \mathrm{QMT}=$ Quadriceps muscle thickness; HGS $=$ handgrip strength.

Limb muscle weakness is a common finding in individuals with COPD, which is evidenced by reduced muscle volume, culminating in decreased strength, which is reported mainly in the quadriceps muscle ${ }^{26,27}$. Based on this theoretical assumption, the evaluation of lower limbs muscle thickness has been recommended in these individuals, since the reduction of muscle volume is associated with worsening physical function ${ }^{12,28}$. Currently, US has been recognized as a promising modality that facilitates the quantification of peripheral muscles, as it is a valid, safe, and non-invasive method ${ }^{29}$. Despite the scarcity of evidence investigating the relationship between peripheral muscle volume and health status in individuals with COPD, a study conducted by Ye et al. is noteworthy, whose findings suggest that the quality and quantity of muscles, measured by US, are associated to HRQoL ${ }^{7}$.

Scientific evidence has demonstrated that the reduction of HGS is associated with decreased pulmonary function ${ }^{30}$, reduced lower limb strength ${ }^{11}$, reduced exercise capacity ${ }^{31}$ and increased risk of mortality in individuals with $\mathrm{COPD}^{32}$. According to the GOLD recommendations for management of COPD based on the patients' health status, studies have investigated the association between health status with $\mathrm{HGS}^{1}$. Ansari et al. demonstrated that HGS reduction occurs mainly in patients with a frequent history of exacerbations and is associated with a reduced health status ${ }^{33}$. Another study showed that perception of health status, assessed by CAT, has a dynamic factor in these individuals. Furthermore, that study showed that a higher HGS was one of independent predictors of a transition to recovery from poor health status for patients ${ }^{34}$. Similarly, in the present study we also showed the association between HGS and health status, as well as we demonstrated the HGS values as an independent predictor.

Quadriceps muscle endurance is well known to be reduced in individuals with COPD, when compared to healthy subjects, regardless of the type of task performed, negatively impacting on functional capacity and consequently on quality of life ${ }^{8}$. A study conducted by Stridsman et al. has demonstrated that the presence of clinically relevant fatigue was associated with high scores on CAT. The authors also suggest individually considering the question number eight of the aforementioned instrument on "energy" to tracking the presence of fatigue in clinical practice. Similarly, our findings demonstrated that the reduction of peripheral muscle endurance was associated with a worse health status, evidenced by the higher CAT score ${ }^{35}$.

We did not observe association between the CAT total score with RMS. Given the scarcity of studies that have investigated the relationship between muscle dysfunction and health status, it is worth mentioning the study conducted by Santos et al., whose objective was to investigate the association between HRQoL and peripheral and RMS. The authors suggest that quadriceps and expiratory muscles strength are able to reflect the impact that impairment of activities of daily living have on the quality of life of individuals with $\mathrm{COPD}^{36}$. A possible explanation for the absence of association in our study may be the fact that the individuals did not present respiratory muscle weakness, and a considerable number of them presented with less severe disease stages ${ }^{9}$.

In addition to the relationships observed in the present study between peripheral muscle dysfunction and health status, 


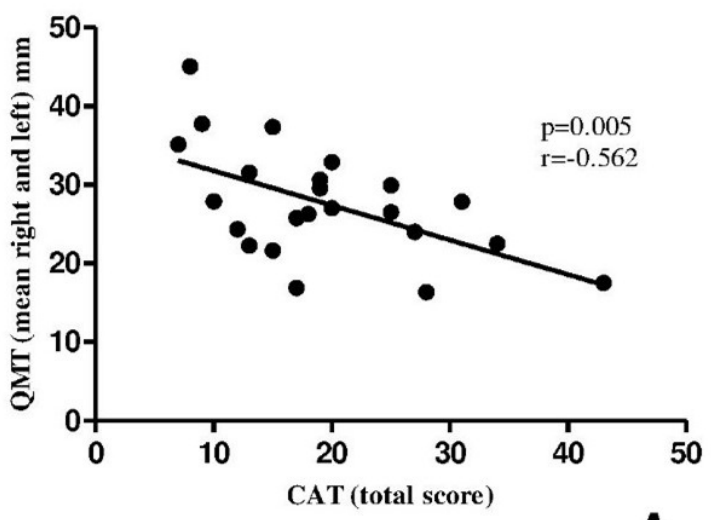

A

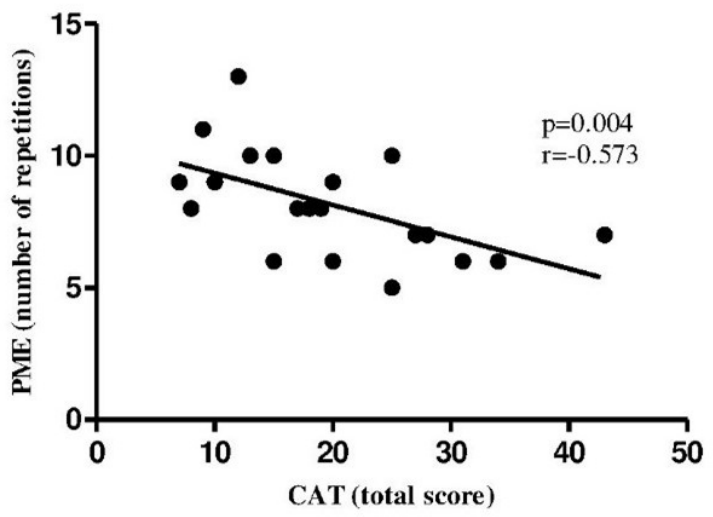

C
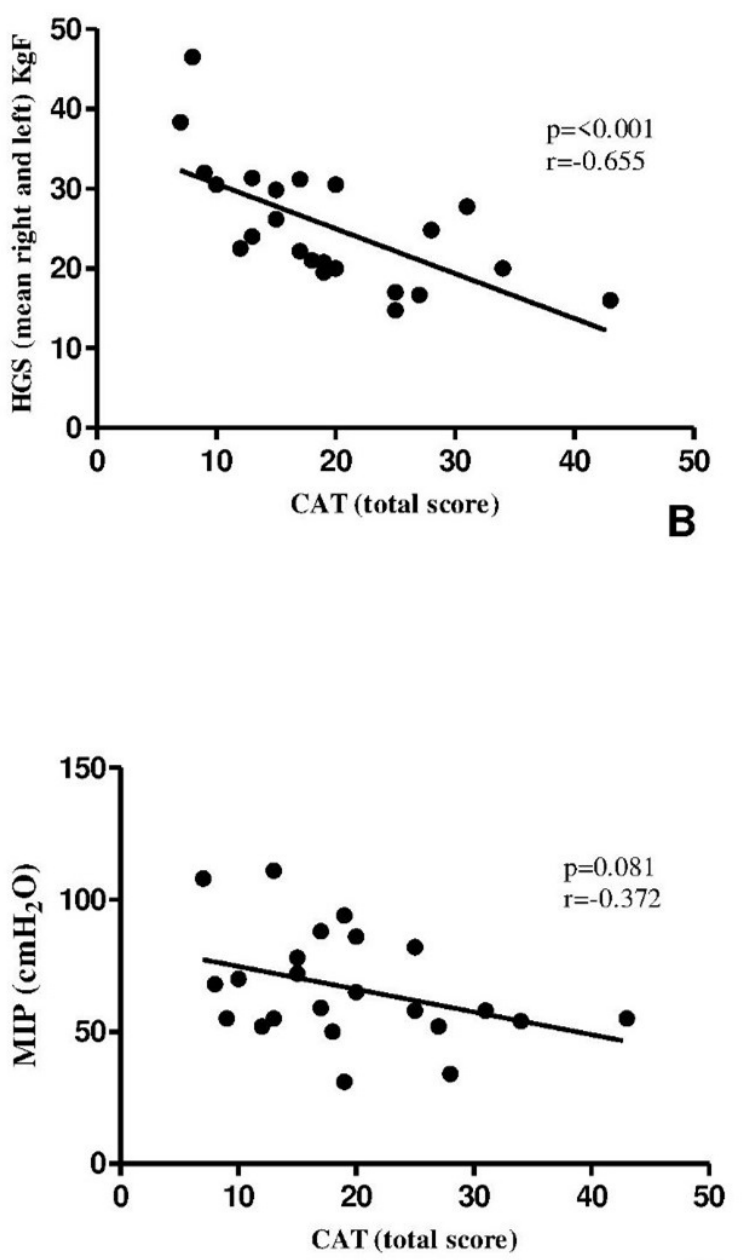

D

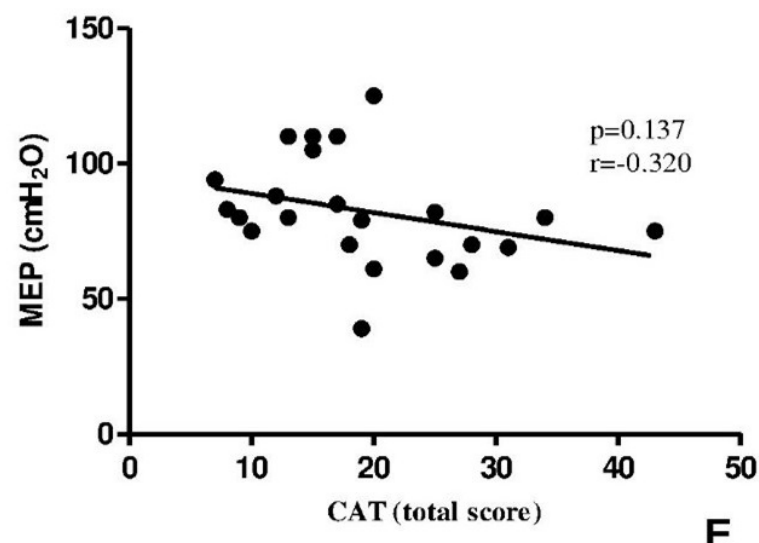

Figure 1. Correlation between the total score on the COPD Assessment Test (CAT) with: A) quadriceps muscle thickness (QMT); B) hand grip strength (HGS); C) peripheral muscle resistance (PMR); D) maximum inspiratory pressure (MIP); E) maximum expiratory pressure (MEP). Significant difference $(\mathrm{p}<0.05)$.

it was demonstrated that QMT, HGS and peripheral muscle endurance were the independent predictors of health status explaining $65 \%$ of the variance. Thus, it is important to mention a recent study whose sample consisted of 3452 individuals with
COPD living in 11 Central and Eastern European countries. The authors identified that the variables depression, number of previous exacerbations, distance walked in the 6-minute walk test (6MWD), $\mathrm{FEV}_{1}(\%)$, modified Medical Research Council 
Table 2. Simple and multiple linear regression between CAT and QMT, peripheral muscle endurance (30-second STS test) and RMS.

\begin{tabular}{|c|c|c|c|c|c|}
\hline Regression & Coefficient $_{\beta}$ & $95 \% \mathrm{CI}$ & $\mathrm{R}^{2}$ & $\mathrm{R}^{2}$ adjusted & $\mathrm{p}$ \\
\hline \multicolumn{6}{|c|}{ Simple linear } \\
\hline QMT & -0.72 & -1.19 to 0.24 & 0.31 & 0.28 & 0.005 \\
\hline HGS & -0.76 & -1.16 to -0.36 & 0.43 & 0.40 & $<0.001$ \\
\hline 30 -second sit-to-stand test & -2.77 & -4.36 to 119 & 0.39 & 0.36 & 0.001 \\
\hline MIP & -0.17 & -0.34 to 0.02 & 0.14 & 0.10 & 0.08 \\
\hline MEP & -0.14 & -0.34 to 0.05 & 0.10 & 0.06 & 0.14 \\
\hline \multicolumn{6}{|c|}{ Multiple linear } \\
\hline QMT & -0.47 & -0.84 to -0.09 & 0.70 & 0.65 & 0.01 \\
\hline HGS & -0.37 & -0.73 to -0.005 & & & 0.04 \\
\hline 30 -second sit-to-stand test & -2.07 & -3.32 to -0.81 & & & 0.002 \\
\hline
\end{tabular}

Significant difference $(\mathrm{p}<0.05) . \mathrm{CI}=$ confidence interval; QMT $=$ Quadriceps muscle thickness; HGS = Handgrip strength; MIP = Maximum inspiratory pressure; $\mathrm{MEP}=$ maximum expiratory pressure.
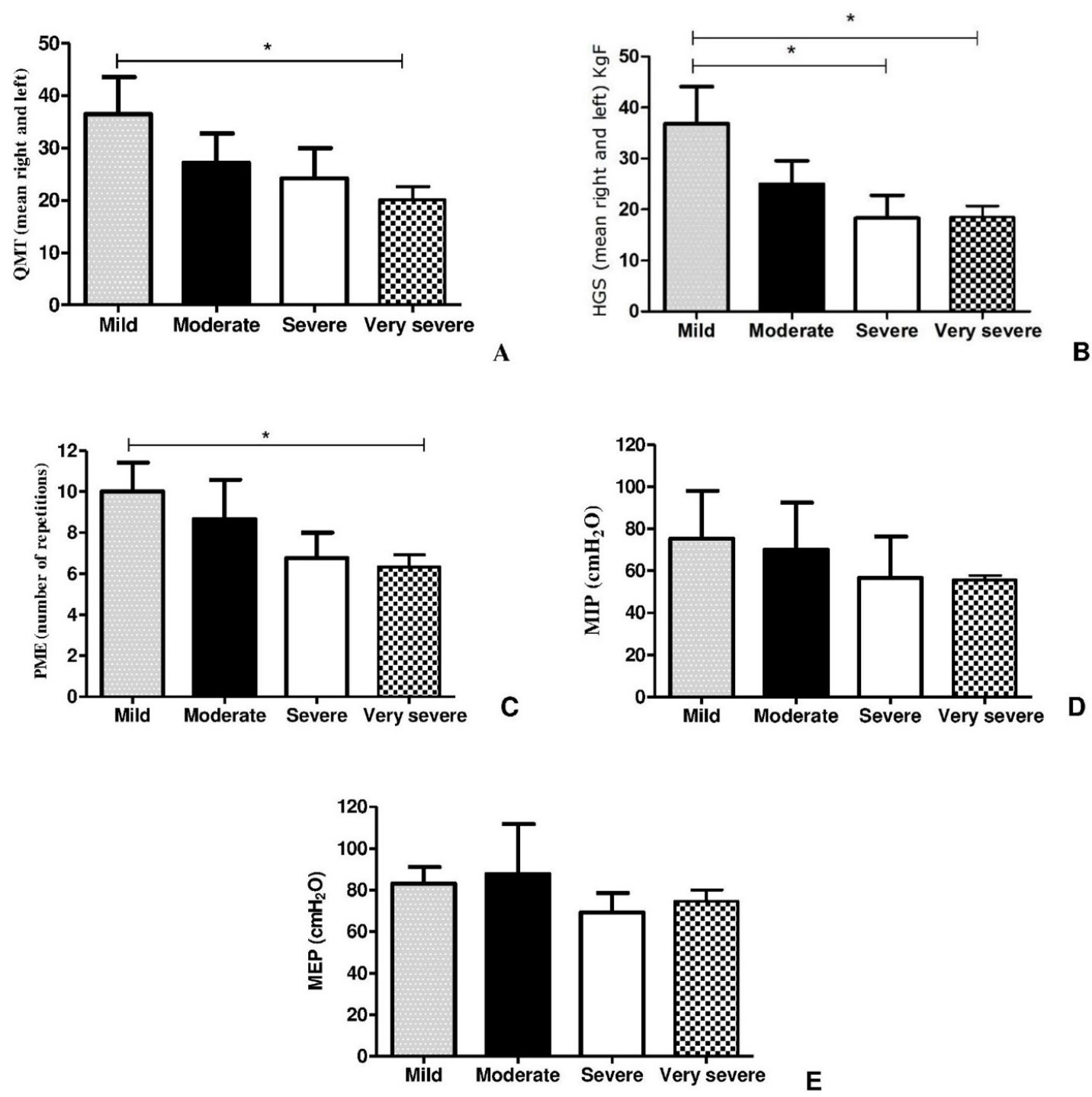

Figure 2. Comparison of the scores obtained in the categories mild $(n=4)$, moderate $(n=12)$, severe $(n=4)$ and very severe $(n=3)$ at the COPD Assessment Test and: A) quadriceps muscle thickness (QMT); B) hand grip strength (HGS); C) peripheral muscle resistance (PMR); D) maximum inspiratory pressure (MIP); E) maximum expiratory pressure (MEP). Significant difference $(\mathrm{p}<0.05)$. 
score and country were significantly associated with the CAT scores, explaining $47.2 \%$ of the variance ${ }^{37}$.

The study by Gulart et al. pioneered the stratification based on the total CAT score. These authors demonstrated a significant difference between mild and high clinical COPD impact for 6MWD, Glittre test time, total score and percentage of the total score obtained on the London Chest Activity of Daily Living (LCADL) scale. Additionally, a significant difference between moderate and high COPD clinical impact on the total score and percentage of the total score obtained on the LCADL scale was observed, thus confirming that the CAT reflects the functional status of individuals with COPD ${ }^{38}$. A significant difference in the clinical impact of the disease between mild and very severe on QMT was identified in our study; mild and severe, and mild and very severe for HGS; and mild and very severe for peripheral muscle endurance. However, this finding should be analyzed with caution, due to the reduced number of individuals belonging to the different categories of the CAT. Therefore, we suggest that the CAT was associated to peripheral muscle dysfunction.

Peripheral muscle dysfunction is a potential risk factor for declining health status over time in $\mathrm{COPD}^{39}$. Considering this premise, the applicability of our findings to clinical practice lies on the fact that the QMT, HGS and peripheral muscle endurance were important determinants of CAT in individuals with COPD. It should be emphasized that such instrument is easy and rapid to apply, besides being validated in Brazil ${ }^{15}$.

This study presents some limitations that must be considered. First, the reduced number of individuals belonging to the different categories regarding the clinical impact of the disease. Second, we performed a multiple regression model in a sample of only 23 individuals. However, we highlight that the sample size was calculated and powered based on the specific correlation between CAT and HGS. Therefore, the sample was considered adequate for this main analysis of our study and the multiple regression model used as a complement. Third, due to the cross-sectional design of the study, the observed relationships are restricted to the evaluated moment, i.e., pre-PR. Fourth, the ultrasonographic analysis of the quadriceps muscle was only assessed by a quantitative variable, not being performed qualitative analysis (echogenicity). Finally, we recognize the need to carefully analyze our results in view of the predominance of women, the small sample number and the inclusion of only ex-smokers or individuals without previous smoking history.

In conclusion, the present study demonstrated that the health status, evaluated by CAT, showed association with QMT, HGS and peripheral muscle endurance in a sample composed predominantly of women with COPD, ex-smokers or without previous smoking history enrolled in a PR program. Conversely, the health status did not denote a relationship with RMS. Our findings also demonstrated that QMT, HGS and peripheral muscle endurance were independent predictors of health status in COPD. Finally, when stratification was considered from the total CAT score, a significant difference was suggested regarding the impact of COPD on health status for QMT, HGS and peripheral muscle endurance. This suggests that the CAT was associated to peripheral muscle dysfunction.

\section{Funding}

This study was financed in part by the Coordenação de Aperfeiçoamento de Pessoal de Nível Superior - Brasil (CAPES) - Finance Code 001.

\section{Conflict of interest}

None.

\section{Acknowledgements}

None.

\section{References}

1. Global Initiative for Chronic Obstructive Pulmonary Disease. Global strategy for the diagnosis, management, and prevention of Chronic Obstructive Pulmonary Disease [Internet]. GOLD; 2019 [cited 2020 July 18]. Available from: https://goldcopd.org/wp-content/ uploads/2018/11/GOLD-2019-POCKET-GUIDE-FINAL_WMS.pdf

2. Barnes PJ, Vestbo J, Calverley PM. The pressing need to redefine “COPD”. Chronic Obstr Pulm Dis (Miami). 2019;6(5):380-3. http:// dx.doi.org/10.15326/jcopdf.6.5.2019.0173. PMid:31710794.

3. Lee H, Jhun BW, Cho J, Yoo KH, Lee JH, Kim DK, et al. Different impacts of respiratory symptoms and comorbidities on COPD-specific health- related quality of life by COPD severity. Int J Chron Obstruct Pulmon Dis. 2017;12(1):3301-10. http://dx.doi.org/10.2147/COPD. S145910. PMid:29180860.

4. Lima TRL, Almeida VP, Ferreira AS, Guimarães FS, Lopes AJ. Handgrip strength and pulmonary disease in the elderly: what is the link? Aging Dis. 2019;10(5):1109-29. http://dx.doi.org/10.14336/ AD.2018.1226. PMid:31595206.

5. Albarrati AM, Gale NS, Enright S, Munnery MM, Cockcroft JR, Shale DJ. A simple and rapid test of physical performance in chronic obstructive pulmonary disease. Int J Chron Obstruct Pulmon Dis. 2016;11(1):1785-91. http://dx.doi.org/10.2147/COPD.S106151. PMid:27536090.

6. Kharbanda S, Ramakrishna A, Krishnan S. Prevalence of quadriceps muscle weakness in patients with COPD and its association with disease severity. Int J Chron Obstruct Pulmon Dis. 2015;10:1727-35. http://dx.doi.org/10.2147/COPD.S87791. PMid:26366065.

7. Ye X, Wang M, Xiao H. Echo intensity of the rectus femoris in stable COPD patients. Int J Chron Obstruct Pulmon Dis. 2017;12:3007-15. http://dx.doi.org/10.2147/COPD.S143645. PMid:29075109.

8. Evans RA, Kaplovitch E, Beauchamp MK, Dolmage TE, Goldstein RS, Gillies C, et al. Is quadriceps endurance reduced in COPD? A systematic review. Chest. 2015;147(3):673-84. http://dx.doi. org/10.1378/chest.14-1079. PMid:25340989.

9. Kim NS, Seo JH, Ko MH, Park SH, Kang SW, Won YH. Respiratory muscle strength in patients with chronic obstructive pulmonary disease. Ann Rehabil Med. 2017;41(4):659-66. http://dx.doi.org/10.5535/ arm.2017.41.4.659. PMid:28971051.

10. Jaitovich A, Barreiro E. Skeletal muscle dysfunction in chronic obstructive pulmonary disease what we know and can do for our patient. Am J Respir Crit Care Med. 2018;198(2):175-86. http://dx.doi. org/10.1164/rccm.201710-2140CI. PMid:29554438. 
11. Barreiro E. Skeletal muscle dysfunction in COPD: novelties in the last decade. Arch Bronconeumol. 2017;53(2):43-4. http://dx.doi. org/10.1016/j.arbr.2016.08.006. PMid:27641307.

12. Maltais F, Decramer M, Casaburi R, Barreiro E, Burelle Y, Debigaré $\mathrm{R}$, et al. An Official American Thoracic Society/European Respiratory Society Statement: Update on Limb Muscle Dysfunction in Chronic Obstructive Pulmonary Disease. Am J Respir Crit Care Med. 2014;189(9):e15-62. http://dx.doi.org/10.1164/rccm.201402-0373ST. PMid:24787074.

13. Karloh M, Rocha SAV, Pizzichini MMM, Cavalli F, Matte DL, Pizzichini E. Is the COPD Assessment Test sensitive for differentiating COPD patients from active smokers and nonsmokers without lung function impairment? A population-based study. J Bras Pneumol. 2018;44(3):213-9. http://dx.doi.org/10.1590/s180637562017000000149. PMid:30043888.

14. Karloh M, Mayer AF, Maurici R, Pizzichini MMM, Jones PW, Pizzichini E. The COPD assessment test: what do we know so far? a systematic review and meta-analysis about clinical outcomes prediction and classification of patients into GOLD stages. Chest. 2016;149(2):413-25. http://dx.doi.org/10.1378/chest.15-1752. PMid:26513112.

15. Silva GPF, Morano MTAP, Viana CMS, Magalhães CBA, Pereira EDB. Portuguese-language version of the COPD Assessment Test: validation for use in Brazil. J Bras Pneumol. 2013;39(4):402-8. http:// dx.doi.org/10.1590/S1806-37132013000400002. PMid:24068260.

16. Jones PW, Tabberer M, Chen WH. Creating scenarios of the impact of COPD and their relationship to COPD Assessment Test (CAT ${ }^{\mathrm{TM}}$ ) scores. BMC Pulm Med. 2011;11:42. http://dx.doi.org/10.1186/14712466-11-42. PMid:21835018.

17. American Thoracic Society/European Respiratory Society. ATS/ERS statement on respiratory muscle testing. Am J Respir Crit Care Med. 2002;166(4):518-624. http://dx.doi.org/10.1164/rccm.166.4.518. PMid:12186831.

18. Pessoa IMBS, Houri M No, Montemezzo D, Silva LAM, Andrade ADD, Parreira V. Predictive equations for respiratory muscle strength according to international and Brazilian guidelines. Braz J Phys Ther. 2014;18(5):410-8. http://dx.doi.org/10.1590/bjpt-rbf.2014.0044. PMid:25372003.

19. Fivez T, Hendrickx A, Van Herpe T, Vlasselaers D, Desmet L, Van den Berghe $G$, et al. An analysis of reliability and accuracy of muscle thickness ultrasonography in critically ill children and adults. J Parenter Enteral Nutr. 2016;40(7):944-9. http://dx.doi. org/10.1177/0148607115575033. PMid:25754437.

20. Fess EE. Grip strength. In: Casanova JS. Clinical assessment recommendations. 2nd ed. Chicago: American Society of Hand Therapists; 1992. p. 41-5.

21. Novaes RD, Miranda AS, Silva JO, Tavares BVF, Dourado VZ Reference equations for predicting of handgrip strength in Brazilian middle-aged and elderly subjects. Fisioter Pesqui. 2009;16(3):217-22. http://dx.doi.org/10.1590/S1809-29502009000300005.

22. Jones CJ, Rikli RE, Beam WCA. 30-s chair-stand test as a measure of lower body strength in community-residing older adults. Res Q Exerc Sport. 1999;70(2):113-9. http://dx.doi.org/10.1080/02701367.1999.1 0608028 . PMid:10380242.

23. Tveter AT, Dagfinrud H, Moseng T, Holm I. Health-related physical fitness measures: reference values and reference equations for use in clinical practice. Arch Phys Med Rehabil. 2014;95(7):1366-73. http:// dx.doi.org/10.1016/j.apmr.2014.02.016. PMid:24607837.

24. de Blasio F, Gregorio AD, Blasio F, Bianco A, Bellofiore B, Scalfia L. Malnutrition and sarcopenia assessment in patients with chronic obstructive pulmonary disease according to international diagnostic criteria, and evaluation of raw BIA variables. Respir Med. 2018;134:15. http://dx.doi.org/10.1016/j.rmed.2017.11.006. PMid:29413494.
25. Jacques SMC. Bioestatística: princípios e aplicações. 1. ed. Porto Alegre: Art Med; 2011.

26. Mathur S, Brooks D, Carvalho CR. Structural alterations of skeletal muscle in copd. Front Physiol. 2014;5:104. http://dx.doi.org/10.3389/ fphys.2014.00104. PMid:24678302.

27. Benz E, Trajanoska K, Lahousse L, Schoufour JD, Terzikhan N, De Roos E, et al. Sarcopenia in COPD: a systematic review and meta-analysis. Eur Respir Rev. 2019;28(154):1-13. http://dx.doi. org/10.1183/16000617.0049-2019. PMid:31722892.

28. Takahashi T, Sugie M, Nara M, Koyama T, Obuchi SP, Harada K, et al. Femoral muscle mass relates to physical frailty components in communitydwelling older people. Geriatr Gerontol Int. 2017;17(10):1636-41. http://dx.doi.org/10.1111/ggi.12945. PMid:28124816.

29. Nijholt W, Scafoglieri A, Jager-Wittenaar H, Hobbelen JSM, Van der Schans CP. The reliability and validity of ultrasound to quantify muscles in older adults: a systematic review. J Cachexia Sarcopenia Muscle. 2017;8(5):702-12. http://dx.doi.org/10.1002/jcsm.12210. PMid:28703496.

30. Strandkvist VJ, Backman H, Röding J, Stridsman C, Lindberg A. Hand grip strength is associated with forced expiratory volume in 1 second among subjects with COPD: report from a population-based cohort study. Int J Chron Obstruct Pulmon Dis. 2016;11:2527-34. http://dx.doi. org/10.2147/COPD.S114154. PMid:27785009.

31. Kyomoto Y, Asai K, Yamada K, Okamoto A, Watanabe T, Hirata $\mathrm{K}$, et al. Handgrip strength measurement in patients with chronic obstructive pulmonary disease: possible predictor of exercise capacity. Respir Investig. 2019;57(5):499-505. http://dx.doi.org/10.1016/j. resinv.2019.03.014. PMid:31085119.

32. Burtin C, Ter Riet G, Puhan MA, Waschki B, Garcia-Aymerich J, Pinto-Plata V, et al. Handgrip weakness and mortality risk in COPD: a multicentre analysis. Thorax. 2016;71(1):86-7. http://dx.doi. org/10.1136/thoraxjnl-2015-207451. PMid:26514408.

33. Ansari K, Keaney N, Taylor I, Burns G, Farrow M. Muscle weakness, health status and frequency of exacerbations in chronic obstructive pulmonary disease. Postgrad Med J. 2012;88(1041):372-6. http:// dx.doi.org/10.1136/postgradmedj-2011-130293. PMid:22388793.

34. Medina-Mirapeix F, Bernabeu-Mora R, Sánchez-Martínez MP, GactoSánchez M, Martín San Agustín R, Montilla-Herrador J. Patterns and predictors of recovery from poor health status measured with the Chronic Obstructive Pulmonary Disease (COPD) assessment test in patients with stable copd: a longitudinal study. J Clin Med. 2019;7(4):946. http://dx.doi.org/10.3390/jcm8070946. PMid:31261894.

35. Stridsman C, Svensson M, Strandkvist VJ, Hedman L, Backman H, Lindberg A. The COPD Assessment Test (CAT) can screen for fatigue among patients with COPD. Ther Adv Respir Dis. 2018;12:1-10. http:// dx.doi.org/10.1177/1753466618787380. PMid:30035671.

36. Santos K, Karloh M, Gulart AA, Munari AB, Mayer A. Relationship between peripheral and respiratory muscle strength and quality of life in patients with chronic obstructive pulmonary disease. Medicina. 2015;48(5):417-24.

37. Miravitlles M, Koblizek V, Esquinas C, Milenkovic B, Barczyk A, Tkacova R, et al. Determinants of CAT (COPD Assessment Test) scores in a population of patients with COPD in central and Eastern Europe: the POPE study. Respir Med. 2019;150:141-8. http://dx.doi. org/10.1016/j.rmed.2019.03.007. PMid:30961941.

38. Gulart AA, Munari AB, Queiroz AP, Cani KC, Matte DL, Mayer AF. Does the COPD assessment test reflect functional status in patients with COPD? Chron Respir Dis. 2017;14(1):37-44. http://dx.doi. org/10.1177/1479972316661924. PMid:27507835.

39. Bui KL, Nyberg A, Rabinovich R, Saey D, Maltais F. The relevance of limb muscle dysfunction in chronic obstructive pulmonary disease a review for clinicians. Clin Chest Med. 2019;40(2):367-83. http:// dx.doi.org/10.1016/j.ccm.2019.02.013. PMid:31078215. 


\section{Author contributions}

TDS, ASP, AFS and IMA: conceptualization of the study; Data acquisition, supervision, analysis and/or interpretation; Writing, revising and/or editing the manuscript; FFP and EL: data acquisition, supervision, analysis and/or interpretation; Writing, revising and/or editing the manuscript.

\section{Author information}

\section{Tamires Daros dos Santos}

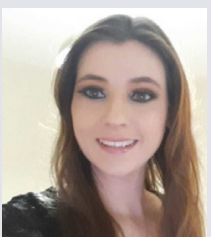

Graduated in Physiotherapy, Universidade Federal de Santa Maria (UFSM), Santa Maria, Rio Grande do Sul, Brazil. Master in Functional Rehabilitation, Universidade Federal de Santa Maria (UFSM), Santa Maria, Rio Grande do Sul, Brazil. PhD Candidate in Human Communication Disorders Graduate Program, Universidade Federal de Santa Maria (UFSM), Santa Maria, Rio Grande do Sul, Brazil.

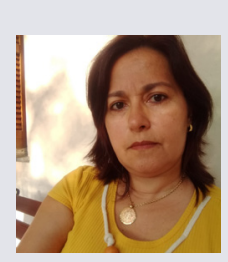

\section{Adriane Schmidt Pasqualoto}

Graduated in Physiotherapy, Universidade Federal de Santa Maria (UFSM), Santa Maria, Rio Grande do Sul, Brazil. PhD in Pneumological Sciences, Universidade Federal do Rio Grande do Sul (UFRGS), Porto Alegre, Rio Grande do Sul, Brazil. Associate Professor, Department of Physiotherapy and Rehabilitation, Universidade Federal de Santa Maria (UFSM), Santa Maria, Rio Grande do Sul, Brazil.

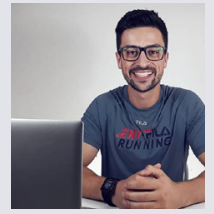

\section{Felipe Fagundes Pereira}

Graduated in physical education, Faculdade Metodista Centenário (FMC), Santa Maria, Rio Grande do Sul, Brazil. Masters Student in Physical Education, Universidade Federal de Santa Maria (UFSM), Santa Maria, Rio Grande do Sul, Brazil.

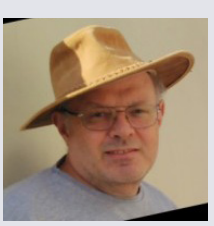

\section{Everton Ludke}

Graduated in Physics Full Degree, Universidade Federal de Santa Maria (UFSM), Santa Maria, Rio Grande do Sul, Brazil. PhD in Astrophysics and Radio Astronomy, University of Manchester, Manchester, Reino Unido. Full professor, Department of Physics, Universidade Federal de Santa Maria (UFSM), Santa Maria, Rio Grande do Sul, Brazil.

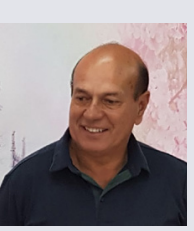

\section{Aron Ferreira da Silveira}

Graduated in Veterinary Medicine, Universidade Federal de Santa Maria (UFSM), Santa Maria, Rio Grande do Sul, Brazil. PhD in Veterinary Medicine, Universidade Federal do Rio Grande do Sul (UFRGS), Porto Alegre, Brazil. Full professor, Department of Morphology, Universidade Federal de Santa Maria (UFSM), Santa Maria, Rio Grande do Sul, Brazil.

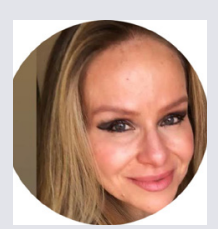

\section{Isabella Martins de Albuquerque}

Graduated in Physiotherapy, Universidade Federal de Santa Maria (UFSM), Santa Maria, Rio Grande do Sul, Brazil. PhD in Medical Sciences, Universidade Federal do Rio Grande do Sul (UFRGS), Porto Alegre, Rio Grande do Sul, Brazil. Associate Professor, Department of Physiotherapy and Rehabilitation, Universidade Federal de Santa Maria (UFSM), Santa Maria, Rio Grande do Sul, Brazil. 